\title{
Impact of Collaborative Learning in Electrical Engineering Education
}

\author{
Franco Aldrin Menezes ${ }^{1}$, Rolen Lionel Rodrigues ${ }^{2}$, Deepesh S Kanchan ${ }^{3}$ \\ ${ }^{1}$ Electrical \& Electronics Engineering Department, St Joseph Engineering College, Mangalore, Karnataka \\ ${ }^{2}$ Electrical \& Electronics Engineering Department, St Joseph Engineering College, Mangalore, Karnataka \\ ${ }^{3}$ Electrical \& Electronics Engineering Department, St Joseph Engineering College, Mangalore, Karnataka \\ 1 francom@sjec.ac.in \\ ${ }^{2}$ rolenr@sjec.ac.in \\ deepeshk@sjec.ac.in
}

\begin{abstract}
Electrical Engineering Education needs the students to have prior knowledge of mathematical tools and analytical skills which warrants the need for collaborative learning. This paper explores the impact of collaborative learning strategies on the academic performance of students in electrical and electronics engineering. The purpose of this paper is to assess the learning of students in courses with a high quotient of analytical thinking and reasoning. The objective is to enhance the learning of students through creative and collaborative activities designed to ignite young minds. Homogeneous groups were formed and instructions related to collaborative activity were read out in class and made available on the learning management system. Students are given five to eight days for submission of results, interim evaluation, and preparation of presentation which is assessed based on published rubrics. The impact of collaborative learning strategies discussed in this paper is targeted towards the positive growth of individual students acquiring technical and managerial skills. The technical training conducted for students necessitates them to have prerequisite knowledge of foundation courses. It is observed that the students who have experienced collaborative learning methods have performed better during technical training. The collaborative activities have shown a positive response from students in the classroom and their performance in exams has improved. Group activities like chart-making, case-based learning, project-based learning and role play exercise can be planned for few topics in any engineering course design to ignite young minds towards technical topics discussed in theoretical courses with no practical content.
\end{abstract}

Keywords: Collaborative learning, Chart building, Role Play, Case based learning, Project based learning.

\author{
Corresponding Author \\ Franco Menezes, Department of Electrical \& Electronics \\ Engineering, St Joseph Engineering College, Vamanjoor \\ Mangaluru \\ francom@sjec.ac.in
}

\section{Introduction}

Engineers, after having obtained their degrees, were supposed to have sufficient academic qualifications to start a life-long career. The rapid changes in society have also generated a demand for more flexible engineers having many more qualifications than just a high level of technical or scientific specialization. Engineering graduates are required to have the ability to learn new technical skills due to rapid changes in technology. Since Electrical Engineering has many courses based on analysis, the paper focuses on assessing Bloom's Levels related to understanding, problem-solving and analyzing abilities of students.

The paper contains details of group activities conducted for courses like Electrical Machines, Power Electronics, Operational Amplifiers \& Linear IC's, Electrical \& Electronics Measurements, and Management \& Entrepreneurship. Previously the courses were designed only to evaluate the memorizing and writing skills of students. Interactions with peers and external stakeholders reinforced the need for active learning pedagogies and new assessment tools to be implemented by engineering educators. The courses listed above are in the first half (third-fifth semester) of engineering education wherein the students are yet to grasp and implement fundamental knowledge. Hence it is imperative to assess higher levels of Bloom's Taxonomy.

Advances in power electronics and changing demands do make necessary changes in the education of power electronics. This concerns the theoretical (lectures) as well as the practical part of the education (P. Bauer \& J.W. Kolar 2003). Collaborative learning methods show that all students acquired knowledge and skills to learn advanced topics in Engineering and management (Raud, Zoja \& Vodovozov, Valery 2010). It is critical to offer students timely responses using a fair, explicit, and systematic process when assessing collaborative work (Veronica Diaz et.al 2010 EDUCAUSE).

It has been observed that the millennial learner has an enhanced learning experience when indulged in hands-on activities like chart building, case-based learning, and project-based learning. These activities are assessed based on individual and group performance and have shown improvement in the academic performance of students in technical and managerial courses offered by the department of electrical and electronics engineering, St Joseph Engineering College. Although the lack of collaborative skills was found to be an initial hurdle for the success of such activities, a constant interruption, deliberation, and interim assessment by the course instructor helped the students to overcome this hurdle. 


\section{Methodology}

The collaborative group activities conducted for undergraduate students of electrical and electronics engineering consisted of group chart building, minor projects and case-based role-play exercises. The methodology/process of implementing these activities are pictorially represented using the flowcharts. The process of implementing group chart building activity is shown in Figure 1.

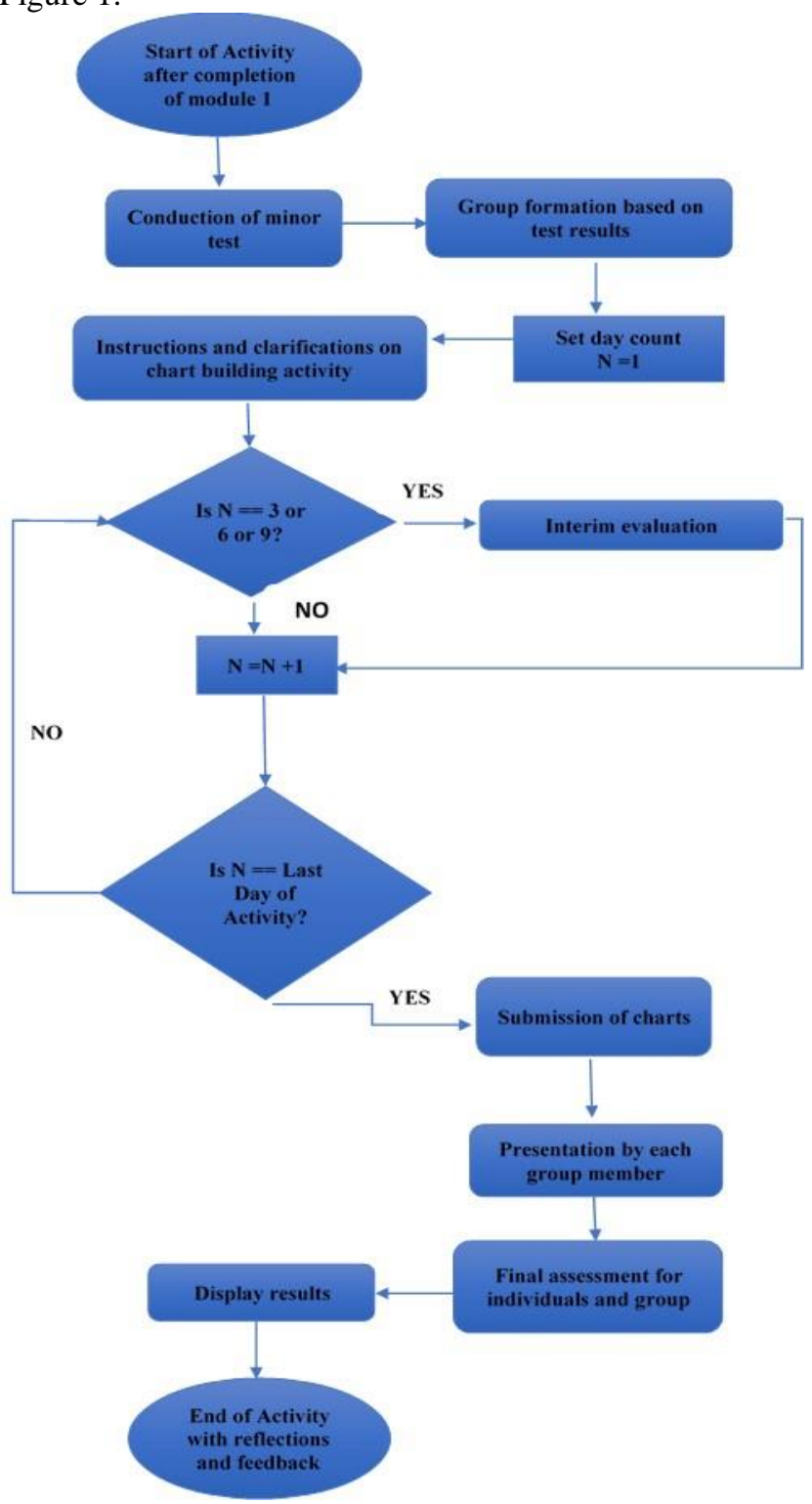

Figure 1: Flow chart of Chart building activity

Figure 1 shows the flow sequence for performing chart building activity for any theoretical course in engineering. The activity begins with the conduction of minor tests after the completion of relevant topics in the syllabus. To reinforce the learning made in chapter 1 , the instructor shall initiate chart building activity by forming homogenous groups based on minor test results. The instructor also provides instructions like the size of the workable area in the chart, type of material/pictures to be used, deadlines for interim evaluation and final evaluation, and rubrics assessing individual and group performance. A total of ten days is provided for completion of this activity with interim evaluations scheduled at the end of day 3 , day 6 , and day 9 . The interim evaluations consist of viva voce, peer evaluation, and a check on the progress of the activity. The final evaluation consists of the submission of chart along with the presentation of ideas depicted in the chart by individual group members. Group members are encouraged to either meet the instructor or to refer the instructional video clip provided in LMS for doubt clearance related to the rules of the activity. This activity is designed to inculcate creativity among students for presenting technical topics since it is well established that inducing creativity into engineering education ignites learning among students. Such chart building activities can be designed for a minimum of six days to a maximum of ten days with sufficient breaks provided for teacher-student interactions.

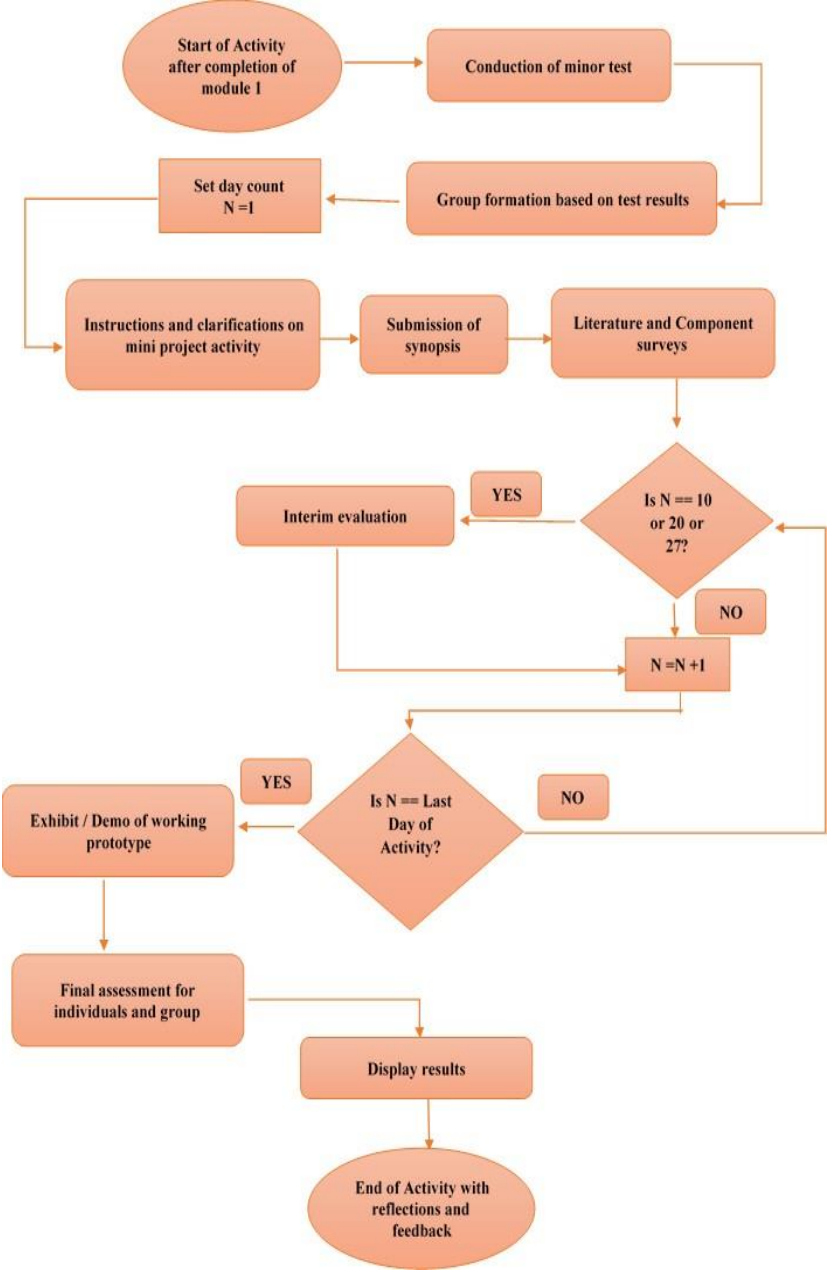

Figure 2: Flow chart of Project based learning activity

Figure 2 shows the process/methodology adopted for collaborative project-based learning. The activity is aimed to kindle hands-on learning among students in theoretical subjects with no add-on practical's. This activity was performed in the fourth, fifth, and sixth semesters for the courses titled operational amplifiers \& linear IC's, power electronics, and mini-projects. The process consist of the conduction of minor tests at the end of completion of relevant topics. The results of this minor test are used in group formation. A homogeneous group of four members is formed to execute mini projects/demo models related to the course. In-class instructions are provided by the instructor 
to give details on rules and regulations, components to be used, submission of the synopsis, and rubrics for interim and final evaluation. An audio/video clip of instructions is also provided in LMS for student reference. The students have to procure the required components from the electronics laboratory and are given a total of 30 days for executing the project work. An interim evaluation is conducted every 10 days to check the design and selection of components, interim results, and demo of the final working model. During these interim evaluations, individual and group performance is assessed based on peer evaluation, the progress of project work, and viva voce. The final evaluation is done by the instructor with the help of a co-faculty member based on the presentation of the working demo in a mini-project exhibition.

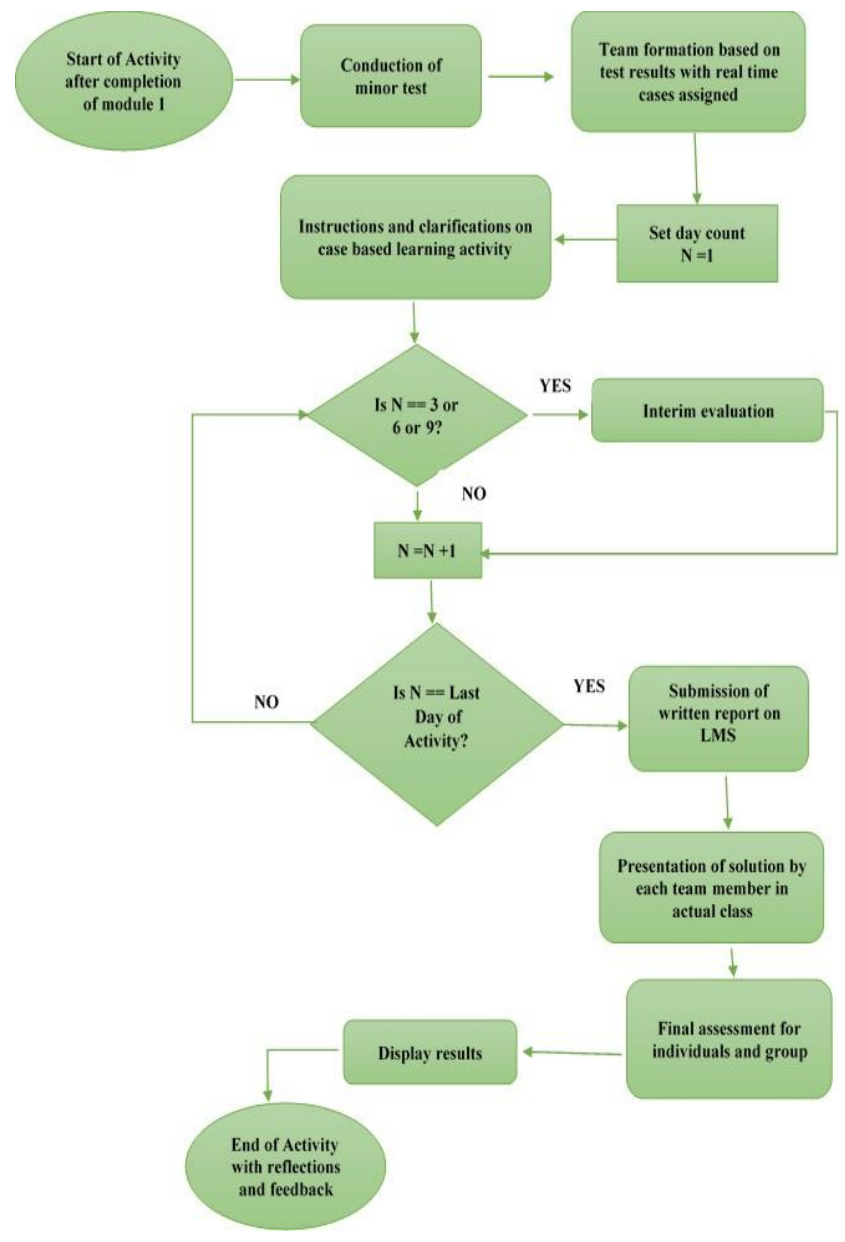

Figure 3: Flow chart of case based role play exercise

Figure 3 shows the process/methodology adopted for the case-based role-play exercise conducted in the course titled "Management \& Entrepreneurship" offered for the fifth semester engineering students. This course is theoretical in nature and has course content on managerial functions namely planning, organizing, actuating, and controlling. A Role-play exercise was conducted wherein each member of the group had to play different managerial roles. A minor test was conducted at the end of relevant topics and the results of the test were used for group formation. The homogeneous groups were provided instructions on rules and regulations, deadlines of submission, rubrics for a written report, and oral presentation. Each group was given a real-time case study which was in the form of a social problem statement. The group had to work together to provide a techno-economical or socio-economical solution to the assigned problem statement. A total of ten days were provided for the groups to submit a written report followed by an oral presentation. Interim evaluations were conducted at the end of the third, sixth, and ninth day to evaluate individual and group performance based on peer evaluation and viva voce. The final evaluation was conducted and assessed based on the presentation skills of individual group members and group cooperation towards the solution of the assigned problem statement.

\section{Results and discussions}

Group chart building activity was implemented by second and third-year electrical and electronics engineering students which have improved their analytical skills since courses like Electrical machines, Electrical Circuits, Machine design requires analysis and deep learning. The groups consisted of four members. These groups were made by the instructor based on pre-test results. Student groups were assigned the tasks to be completed in ten days with assessment done every three days on an individual one to one basis.

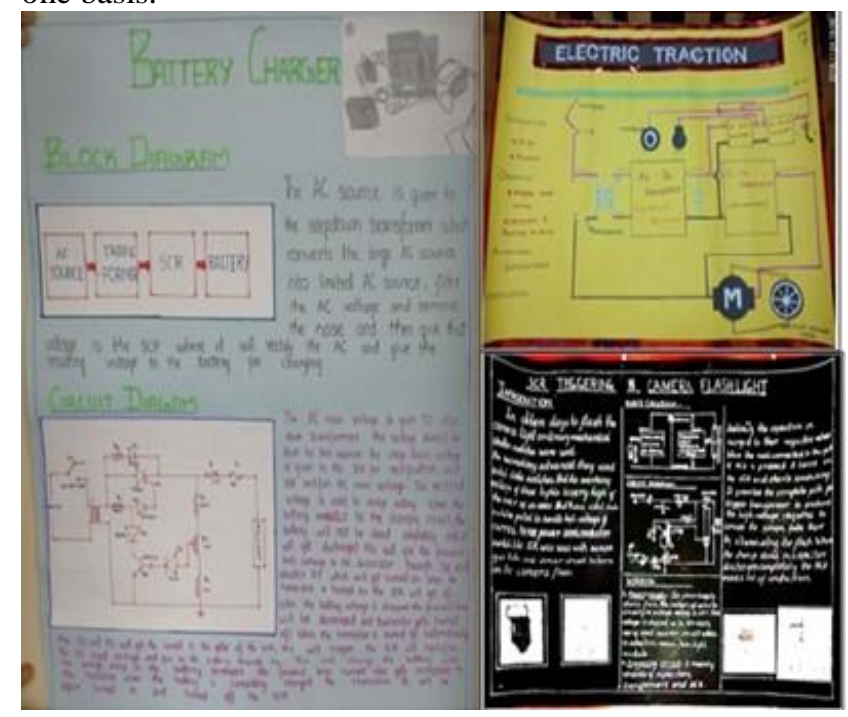

Figure 4 Sample results of chart building activity

Figure 4 shows the collage of charts prepared by student groups at the end of the group chart building activity for the course on power electronics. A survey was conducted for a total of 184 students to find the effectiveness of collaborative learning activities. It was found that $91 \%$ of the students agreed that their learning experience was enhanced by group chart building activity. $91 \%$ of the students felt that group cooperation was effective in group chart building activity.

It is observed from Figure 5 that $90 \%$ of the students agreed to the fact that the chart building activity had a good impact on knowledge sharing related to topics of power electronics, electrical machines, and electrical measurement courses. 
Effectiveness of Knowledge Sharing - Chart Building Activity

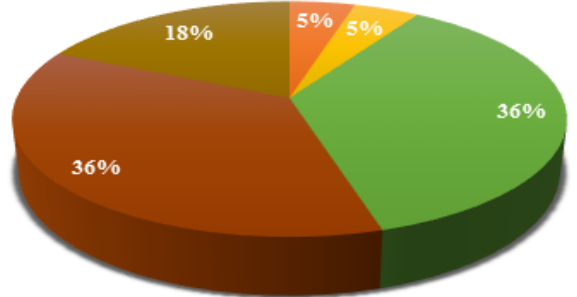

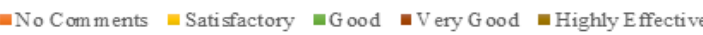

Figure 5: Effectiveness of Knowledge shared - Chart Building

Project-based collaborative learning methods were implemented for fourth and sixth semester electrical and electronics engineering students which indicated a positive impact on student performance in internal and external exams. The students responded with innovative solutions to problem statement by implementing mini-projects working in groups. The groups consisted of four members. These groups were formed by the instructor based on minor test results to complete the given task in four weeks with periodic assessment done on an individual one to one basis.

The effectiveness of project-based collaborative learning was assessed through a survey that was answered by 184 students. These students had experienced this learning pedagogy in the fourth and sixth semesters. It was found that $96 \%$ of the students had a good collaborative learning experience with the project-based learning method. It was found that $96 \%$ of students experienced good group cooperation for this activity. Figure 6 describes the effectiveness of knowledge shared through project-based collaborative learning. It can be seen that $96 \%$ of the students felt that this kind of activity had a good impact on the knowledge shared and gained by them for topics in the courses of operational amplifiers \& linear IC's and power electronics.

Effectiveness of Knowledge Sharing - Project Based Learning

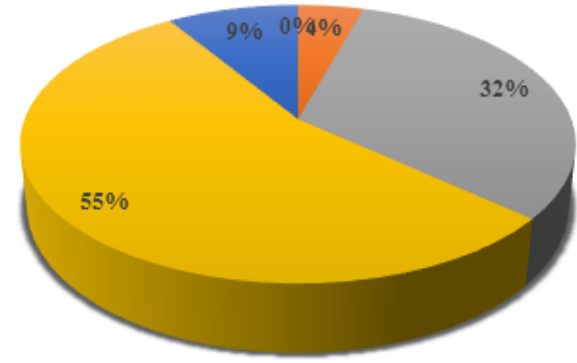

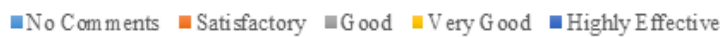

Figure 6: Effectiveness of Knowledge shared - Project Based Learning

The sample of demo models/mini projects done by students is shown in Figure 7.

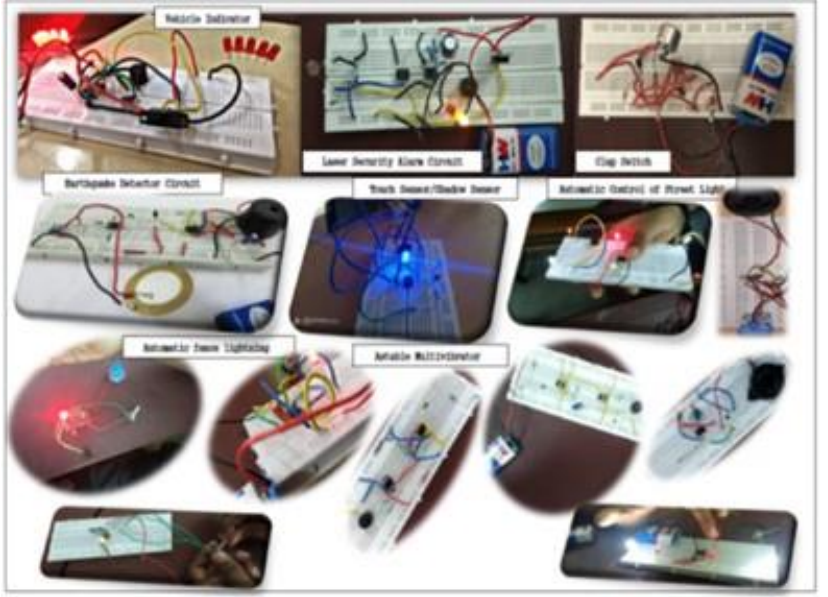

Figure 7: Sample Demo models / mini projects

Case-based learning was implemented in theoretical courses like Electrical \& Electronics measurements, Management \& Entrepreneurship to enhance the ability to understand new topics and real-life problem-solving skills of students. Technical/social cases were given to groups of four members with either a paragraph or a theme of the instructor's choice. Three themes were announced as reallife problems. Students within a group had to play the roles of managers to implement a solution related to planning and organizing. The effectiveness of case-based learning was assessed through a survey that was answered by 184 students. These students had experienced this learning pedagogy in the second and third year. It was found that 95\% of the students had a good learning experience with case-based role-play exercises. It was found that $91 \%$ of students experienced good group cooperation for this activity. Figure 8 describes the effectiveness of knowledge shared through case-based role-play exercise. It can be seen that $91 \%$ of the students felt that this kind of activity had a good impact on the knowledge shared and gained by them for topics in the courses of management \& entrepreneurship and electrical \& electronics measurement.

Effectiveness of Knowledge Sharing - Case Based Role Play

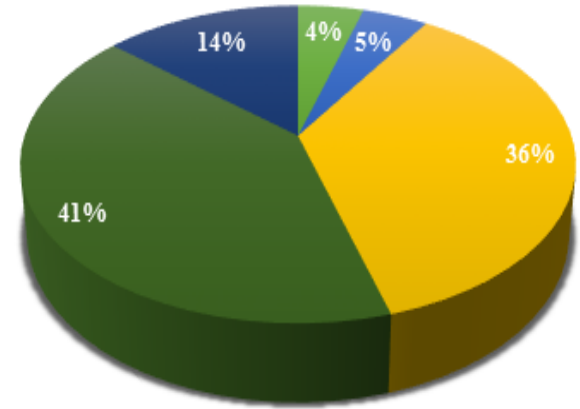

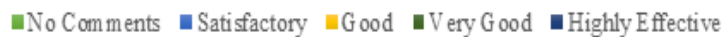

Figure 8: Effectiveness of Knowledge shared - Case Based Role Play Exercise

Roleplay exercises enhance the presentation skills and problem-solving skills of students when they encounter real-time problems. The above survey was conducted at the end of the semester for analysis and to dwell on the future scope for improvement. 
Figure 9 shows the impact of all the collaborative learning methods discussed in this paper.

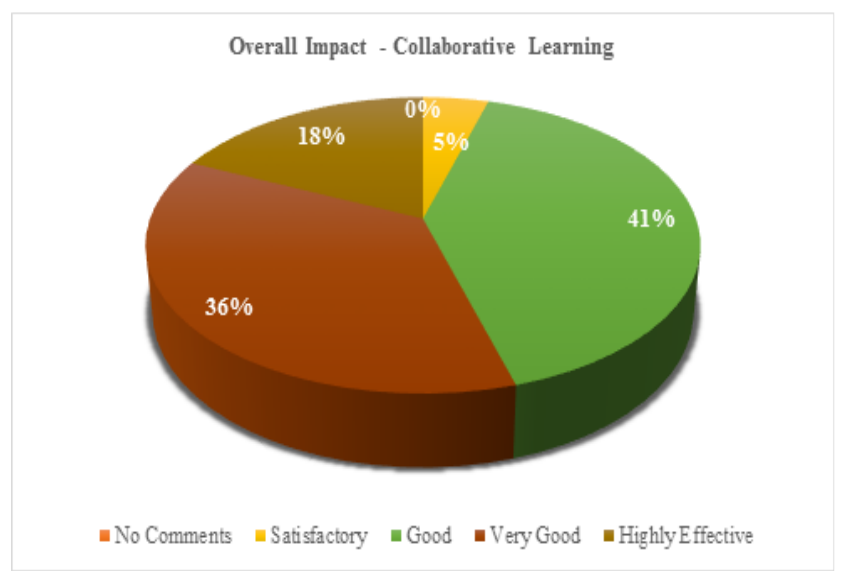

Figure 9: Overall Impact - Collaborative Learning

It is observed that $95 \%$ of the students have experienced a positive impact on their learning of technical topics during the second and third year of engineering studies.

\section{Conclusion}

Most engineering courses though practical do not have sufficient practical components in course design. Due to constraints of internal and external evaluation, students and teachers resort to a one-way memory-based teachinglearning approach. The retention level in students when they reach the final year of graduation is insufficient for competition success. The impact of collaborative learning strategies discussed in this paper is targeted towards the positive growth of individual students acquiring technical and managerial skills. The technical training done for students in the final year necessitates the students to have certain prerequisite knowledge of foundation courses. It has been observed that over $90 \%$ of the students have an enhanced learning experience with collaborative learning methods. Student feedback also suggests that $95 \%$ of the students have experienced an improvement in knowledge gained in relevant topics of theoretical courses prescribed in the syllabus of electrical and electronics engineering. The collaborative group activities have shown a positive response from students in the classroom. Such activities can be planned for a few topics in any engineering course design to ignite young minds towards technical topics discussed in theoretical courses with no practical content.

\section{Acknowledgement}

The authors of the paper would like to acknowledge the support and guidance provided by the Management of St Joseph Engineering College, Mangaluru for executing the components of this work. We would also like to express our gratitude to IUCEE for its certification program which has motivated us to pursue Engineering Education Research.

\section{References}

Assessment of Collaborative Learning Project Outcomes, 2010 EDUCAUSE, This work is licensed under a Creative Commons Attribution-Non Commercial-Share Alike 3.0 License
P. Bauer \& J.W. Kolar (2003) Teaching Power Electronics in the 21st Century, EPE Journal, 13:4, 43-50, DOI: 10.1080/09398368.2003.11463546

Raud, Zoja \& Vodovozov, Valery (2010) Project-Based Collaborative Learning of Electrical Engineering Master Students, 2010 IEEE Education Engineering Conference, EDUCON 2010,DO:10.1109/EDUCON.2010.5492337 Veronica Diaz, Malcolm Brown, and Janet Salmons, 